\title{
Chapter I3
}

\section{Uncertainties in Metering Stormwater Flows}

\author{
Steven J. Wright
}

Modern stormwater management often involves the development of numerical hydrologic/hydraulic models in order to provide decision making tools regarding placement of retention facilities, in-system storage, etc. Since many existing combined sewer systems are inadequately characterized and metered, flow meters are often installed in order to provide data sets for calibrating such models. Primary metering devices such as Parshall flumes or venturi meters are often unacceptable because of their high losses and the need to avoid surcharging during high flow conditions. Low loss meters typically utilize velocity measurements to estimate discharge and the accuracy of these types of meters may be less than that associated with primary meters which is reported to be 0.5 to $1 \%$ for orifice and venturi meters (Pomroy, 1996) and 5\% for Parshall flumes (Parshall, 1926). In a recent hydraulic model development for the city of Detroit, Michigan, the stated goals for the model calibration were to predict the peak discharge to within $20 \%$ and the total flow volume to within $10 \%$ of the values recorded at select metering stations (Camp, Dresser \& McKee, 1993a). In this particular application, two semi-independent methods were available for estimating the metered discharge. An analysis of the discharges predicted by these two methods indicated significant discrepancies under certain flow conditions, raising questions regarding the ability of the meters to resolve flow rates and volumes to within the stated calibration goals. The subsequent investigation of

Wright, S.J. 1997. "Uncertainties in Metering Stormwater Flows." Journal of Water Management Modeling R195-13. doi: 10.14796/JWMM.R195-13.

(C) CHI 1997 www.chijournal.org ISSN: 2292-6062 (Formerly in Advances in Modeling the Management of Stormwater Impacts. ISBN: 0-9697422-7-4) 
meter uncertainty is discussed in this chapter. A review of the metering systems indicates the possibilities of considerable differences between the independent discharge measurements; this is verified by a comparison for selected discharge events.

\section{I3.I Sources of Metering Uncertainty}

Formal methodology is generally available for making estimates of measurement uncertainty (ISO 5168), however the types of data available in many applications is insufficient to fully implement the specified procedures. Nevertheless, the basic concepts may still be applied in order to derive an estimate of the uncertainty associated with a measurement or set of measurements.

The purpose of a general uncertainty analysis is to obtain an estimate of the largest error expected to remain with the measurement of a particular quantity such as flow rate. Measurement errors inay be subdivided into precision and bias errors. Precision errors may be considered to be random deviations from the true value of a measured quantity that are associated with limitations in the ability of the measurement apparatus or procedure to resolve the measurement. Bias, on the other hand, refers to a constant or systematic deviation between the true and measured values of a particular quantity. Bias error is particularly difficult to quantify in many applications because feasible methodology is not available for determination of the "true" value of the quantity of interest; a master meter or some other independent (and less uncertain) means of measuring the flow would be required to estimate the bias in a metering application. Precision uncertainty, however, may be estimated by repeated measurements at the same condition with the sample standard deviation $\mathrm{S}$ used to represent the precision or repeatability of the measurement. Even precision uncertainty is difficult to estimate in the metering of stormwater flows as the discharge is typically unsteady and it cannot be guaranteed that the meter is recording the same flow rate during the course of repeated measurements.

Measurement errors can be categorized into three elemental sources namely (i) calibration errors; (ii) data acquisition errors; and (iii) data reduction errors, each of which has a bias and a precision component. Data reduction errors would most likely be associated with limitations in the ability of a calibration equation to "fit" observed data over a range of conditions due to systematic deviations or bias between the calibration equations and the data. Calibration errors, on the other hand, may be associated with both bias and precision errors in components of both the master meter used to define the "true" discharge and the meter being calibrated. Again, it is important to recognize that it may be impossible to define the true discharge in a specific application and therefore the bias error cannot be accurately estimated. Estimates of precision errors during calibration may be 
determined by repeating each calibration flow several times and computing the sample standard deviation although this approach is generally not followed in a typical calibration. In the case where the calibration is obtained under the assumption of a constant meter coefficient (i.e. a particular functional representation of the metering equation is assumed with a discharge coefficient or other calibration constant applied to the function), all data collected during the calibration may be ensembled in order to determine the sample standard deviation $\mathrm{S}$. While the uncertainty in an individual measurement may be related to $\mathrm{S}$, the uncertainty in the meter coefficient (the calibration error) would be better characterized by the standard error of estimate $S_{e}=S / \sqrt{N}$ with N the number of individual calibration points. This characterization implicitly assumes that there is no data reduction error, i.e. that there is no bias between the actual flow and the functional representation of the calibration equation.

Assuming that estimates can be derived for both bias and precision errors for each of the elemental errors listed above, these can be combined into an overall uncertainty estimate. This is performed by computing the root-sum-square of both the bias and the precision error (e.g. $\mathrm{S}^{2}=\mathrm{S}_{1}{ }^{2}+\mathrm{S}_{2}{ }^{2}+\mathrm{S}_{3}{ }^{2}$ where $\mathrm{S}$ is the estimate of the overall precision error and $S_{i}$ refers to the estimates of the individual components of calibration, data acquisition, and data reduction). Finally, the bias and precision uncertainties can be combined to determine an estimate of the overall uncertainty (ISO 5168). While this procedure is relatively straightforward, its implementation is often impossible due to the inability to define the bias components to the overall uncertainty and due to an insufficient number of measurements to properly characterize the precision uncertainty in the calibration. In light of this, the results presented in the case study that follows implement the spirit of this formal procedure while recognizing that additional information would need to be developed in a complete uncertainty analysis. This approach is typical of many metering applications (Dearden, 1992) in which estimates of uncertainty are to be developed.

Since most meters do not measure discharge directly, it is necessary to infer discharge from the measurement of one or more uncertain variables. In this situation it is necessary to investigate the propagation of uncertainty through the function that is used to compute the discharge:

$$
Q=f\left(x_{i}\right)
$$

where:

$$
\begin{aligned}
x_{i}= & \text { the individual variables that enter into the computation } \\
& \text { of the discharge. }
\end{aligned}
$$

Under the assumption of small uncertainties, the uncertainty in Q may be estimated by the linear terms in a Taylor's series expansion about a base value: 


$$
d Q=\frac{\partial f\left(x_{i}\right)}{\partial x_{1}} d x_{1}+\frac{\partial f\left(x_{i}\right)}{\partial x_{2}} d x_{2}+\cdots
$$

where:

$$
\begin{aligned}
d Q= & \text { the uncertainty in the discharge and } \\
d x_{i}= & \text { the uncertainty in each of the measured variables that } \\
& \text { enter into the determination of } Q .
\end{aligned}
$$

Alternatively, uncertainty estimates may be obtained by simply inserting the ranges of each of the variables into the meter equation $\mathrm{f}\left(\mathrm{x}_{\mathrm{i}}\right)$ and determining the maximum range in $\mathrm{Q}$.

For stormwater metering applications, the uncertainties can be grouped into three main categories:

- meter precision,

- calibration, and

- extrapolation.

Meter precision involves the impacts of the individual components of a discharge measurement (depth, velocity etc.) on the discharge computed from the meter output and can be due to both bias and random error (Granger, 1988). It is generally difficult or impossible to determine systematic errors in measurements due to the lack of an independent method for verifying the discharge being reported. Attempts to remove the bias error may be made by calibrating the meter in-situ by comparing the reported discharge against an independent measurement. However, both methods for recording discharge are still subject to precision uncertainties and discharges cannot be considered to be verified except to within the combined uncertainties of the two measurement methods. This uncertainty can be reduced by calibrating over multiple events and averaging the results. Extrapolation errors could arise from utilizing the meter outside the range of flow conditions for which the calibration was determined if there are bias errors in the methodology used for metering flow. This is important because insitu calibration is often restricted to dry weather flow conditions which may involve discharges substantially less than those associated with the storm events for which numerical models are typically calibrated.

\subsection{Case Study}

The Detroit sewer system consists of a combination of combined and separate sewer systems with the central, older portion of the system being primarily combined sewers. Flows from the suburbs are often separated but feed into the central system. Twelve new flow meters were installed in the spring of 1992 for the purpose of calibrating the stormwater flow model for the central city. These meters were installed in sewers ranging from 0.61 to $4.72 \mathrm{~m}$ in 
diameter and were calibrated in-situ over the period April-June, 1992. Details of the meter calibrations are discussed below. Four rainfall events in the spring and summer of 1993 were selected for calibration of the hydraulic model. Difficulties were experienced with the attempts to predict reported discharges at several meter stations. This case study reviews the attempts to quantify the measurement uncertainty in these meter installations.

\subsubsection{Description of Metering Systems}

The two semi-independent methods of discharge metering involve measurements from a single metering installation. The elements of the meter station include a pressure transducer to determine the flow depth and an acoustic Doppler meter, both of which are mounted at the pipe invert. The pressure transducer output was converted directly into depth from which the sectional characteristics such as the area and hydraulic radius could be computed from the known pipe diameter. The acoustic Doppler meter sends a signal of known frequency through the flow which is subject to a Doppler shift after interaction with particles carried with the flow. This Doppler shift is proportional to the particle velocity, but since there are velocity variations throughout the flow depth, a range of frequencies is received by the meter. The meter functions by analyzing the frequency spectrum and determining the peak frequency which in turn relates to the peak velocity in the flow section. A separate calibration was utilized to relate the average velocity to the peak value and this is subsequently converted into discharge by multiplying by the flow area determined from the depth sensor. This type of metering procedure is distinct from other acoustic Doppler meters (acoustic Doppler current profilers or ADCPs) in which the discharge is estimated by measuring the velocities at a number of locations within the flow cross-section and summing the contributions of the products of local velocities and sub-areas (e.g. Gordon, 1989).

All meters were calibrated in-situ to determine meter coefficients. A number of calibration events (of the order of 6 to 10 per meter) were performed during dry weather flow conditions during April-June, 1992. Generally the calibration flows were at substantially smaller flow depths than experienced during the storm events for which the hydraulic model was calibrated. For example, the calibration conditions for a particular meter (HUF1) involved flow depths in the range of 0.45 to $0.58 \mathrm{~m}$ in a $4.11 \mathrm{~m}$-diameter sewer; peak storm discharges sometimes approached the full flow condition.

During the calibration event, the flow depth at the center of the channel was measured with a staff gauge. The installed meter was functional during the calibration so that the pressure transducer output could be directly compared to the staff gauge reading. 
Velocity calibrations were performed using the three point method described by ISO 748 (1994) in which the local velocities were measured at 0.2 , 0.6 and 0.8 of the flow depth by a Marsh McBirney velocity meter. These velocities were measured at three locations, one at the center of the channel and the other two at roughly the quarter points. The average velocity flow velocity was computed by taking the arithmetic average of these nine velocities except that the 0.6 depth velocity was weighted twice according to ISO 748 . The discharge was then computed from the product of the average velocity and the flow area determined from the measured depth and the pipe diameter. The peak velocity was also estimated by measuring velocities in a variety of locations throughout the flow cross-section and recording the maximum value. This peak velocity can be directly compared to the acoustic Doppler meter output while the average velocity was used to establish a conversion from the peak to average velocity.

\subsubsection{Discharge Metering Methods}

The first method estimates the discharge from the measured depth (from the pressure transducer) and an application of the Manning equation; this discharge is hereafter referred to as $Q_{\text {Manning }}$. This method for metering flow is dependent upon an assumption of uniform flow which may not be the case for a number of reasons. There may be backwater effects at the meter station due to restrictions further downstream. In addition, there may be nonuniform flow due to the rising and falling hydrographs during a storm event as the water surface slope may exceed the bottom slope during a rising hydrograph and be less than it for a falling hydrograph.

The specific procedure for the determination of discharge is to calibrate a station-dependent hydraulic coefficient $\mathrm{HC}$ which is essentially equal to $\mathrm{S}_{\mathrm{o}}{ }^{1 / 2} / \mathrm{n}$ with $S_{0}$ the sewer slope and $n$ the Manning resistance coefficient. This is used in the following equation to compute discharge:

$$
Q_{\text {Manning }}=\frac{1.486 A R_{h}{ }^{2 / 3} H C}{F_{n}}
$$

where:

$1.486=$ the units factor for US customary units,

$A=$ the flow area (determined from the depth recorded by the pressure transducer and the known pipe diameter),

$R_{h}=$ the hydraulic radius, and

$F_{n}=$ a resistance correction factor for partially full flow in a circular conduit that is based on the variation in Manning $n$ suggested by Camp (1946). $F_{n}$ varies from 1.0 (zero and maximum relative depths) to 1.22 (at a relative depth of 0.3 ). 
The hydraulic coefficient HC is solved from Equation 13.3 for each calibration event using the calibration discharge and the area and hydraulic radius terms which are computed from the measured depth. HC is assumed to be a constant for a particular meter station. Uncertainties during the calibration events include both the precision uncertainties associated with the determination of average velocity and the depth and are considered to be reflected directly by the variation in $\mathrm{HC}$ among calibration events. During a real metering application, uncertainties in discharge measurement using this method include the precision uncertainty in the depth measurement (as it affects the area and hydraulic radius terms), the calibration uncertainty in $\mathrm{HC}$, and any possible extrapolation uncertainties that may exist. Extrapolation uncertainties may be associated with backwater or other nonuniform flow effects at the particular meter station, the lack of validity of the specific $F_{n}$ correction, or other unknown effects.

The second discharge metering method is referred to as $\mathrm{Q}_{\text {Continuity }}$ and is simply computed as the product of the flow area and average velocity. The depth was measured by the pressure transducer and the flow area computed from the depth and the known pipe diameter. The mean velocity is estimated from the peak velocity registered by the acoustic Doppler meter as discussed previously and converted to the average velocity by utilizing an average to peak velocity ratio $R$ $=\mathrm{V}_{\text {average }} / \mathrm{V}_{\text {peak }}$ which was determined by calibration. $\mathrm{R}$ was assumed to be constant (independent of depth, etc.) at a particular metering station based on experience with the meters in previous installations but the average values determined for the different metering stations varied from 0.75 to 0.93 . In addition, the calibration procedure involved the adjustment of the acoustic Doppler meter gain so that the peak velocities measured with the Doppler meter during the calibration event agree with those measured by the Marsh McBirney meter. Uncertainties in this method involved precision uncertainties in the computation of flow area (through the measured depth) as well as the peak velocity. Calibration uncertainties are due to several factors including the uncertainty in the $\mathrm{R}$ value, the uncertainty in the flow area and the uncertainty in the peak velocity measurement. Extrapolation uncertainties could be introduced by systematic variations in $\mathrm{R}$ with depth of flow or other unknown effects.

\subsubsection{Estimates of Meter Uncertainty}

Data recorded during the calibration events were reviewed to obtain estimates of the uncertainties associated with discharge measurements. This data included both the records from the installed meter as well as the independent measurements of depth and velocity collected during the calibration events. The installed meter recorded both depth and peak velocity while the calibration reported depth, peak velocity, and average velocity (as determined by the procedure for averaging the nine point velocities). Deviations among these data 
were analyzed in order to obtain estimates of meter uncertainty. Independent estimates of meter uncertainty for several of the flow meters were estimated by the vendor that installed the meters (Camp, Dresser \& McKee, 1993b). Some aspects of these estimates are similar to those presented below but rely more on the precision estimates recorded by field personnel who were involved in the calibration measurements. Uncertainties estimated for dry weather flows generally ranged from 5 to $15 \%$ and independent uncertainties (with no formal basis) about twice the dry weather values were assigned to wet weather events. This range of uncertainties can be compared to a precision error estimate of $0.4 \%$ and bias errors of the order of $5 \%$ estimated for river discharge measurements with an acoustic Doppler current profiler (Gordon, 1989).

\section{Precision Uncertainty}

Estimates of the precision uncertainty in the depth measurements were obtained by comparing the two depths recorded (one by the meter and the other by a staff gauge) during a calibration event. The standard deviation (over all calibration events) of the difference between the depths was taken to be an estimate of the uncertainty in depth measurement. These standard deviations were typically of the order of about $2 \%$ of the measured depth for most meter installations. Results for specific meters are presented in Tables 13.1 and 13.2. This range is consistent with the precisions recorded on the calibration sheets by the field personnel regarding their estimates of the measurement precision associated with the measurement of depth from the staff gauge. These standard deviations in depth are used to estimate uncertainties in area and hydraulic radius which ultimately influence discharge measurement.

Table 13.1 Estimates of uncertainty in discharge measurement by $Q_{\text {Manning }}$ for three flow meters.

\begin{tabular}{||l|ccc||}
\hline Type of Uncertainty & \multicolumn{3}{|c|}{ Meter } \\
\hline & HUF1 & SOF1 & NWF2 \\
HC uncertainty & $1.7 \%$ & $2.2 \%$ & $3.5 \%$ \\
& & & \\
Depth Measurement & $2.5 \%$ & $2.5 \%$ & $0.9 \%$ \\
Area Error & $5.0 \%$ & $5.0 \%$ & $1.8 \%$ \\
Extrapolation Uncertainty & 34 & 34 & $40 \%$ \\
QManning Uncertainty & $\approx 41 \%$ & $\approx 41 \%$ & $\approx 45 \%$ \\
\hline
\end{tabular}

Note : Estimate in $\mathrm{HC}$ uncertainty obtained from standard deviation divided by square root

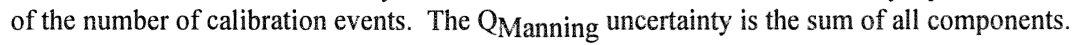


The process for estimating the precision uncertainty for the velocity measurements is more convoluted because of the procedures employed. Each calibration sheet recorded an estimated precision of the velocity measurement from the Marsh McBirney meter and this was used directly as an estimate of the precision uncertainty of that meter. In addition, both the acoustic Doppler and the Marsh McBirney meters registered a peak velocity at the time of the calibration. The standard deviation of differences between these (over all calibration events) was computed and used as an estimate in the uncertainty in the peak velocity recorded by the acoustic Doppler meter. This standard deviation was always greater than the reported precision of the Marsh McBirney meter and was typically of the order of $10 \%$ of the peak velocity. Values are reported for specific meter installations in Table 13.2. The uncertainty in the velocity conversion factor is the standard deviation of the $\mathrm{R}$ (average to peak velocity ratio) values.

Table 13.2 Estimates of uncertainty in discharge measurement by $Q_{\text {continuity }}$ for three flow meters.

\begin{tabular}{|l|ccc||}
\hline Type of Uncertainty & \multicolumn{3}{|c|}{ Meter } \\
\hline & HUF1 & SOF1 & NWF2 \\
Depth Measurement & $2.5 \%$ & $2.5 \%$ & $0.9 \%$ \\
Area Error & $5.0 \%$ & $5.0 \%$ & $1.8 \%$ \\
& & & \\
Velocity Precision & $4 \%$ & $7 \%$ & $4.5 \%$ \\
Velocity Measurement & $6 \%$ & $10.5 \%$ & $8.6 \%$ \\
Velocity Conversion Factor & $5 \%$ & $3.5 \%$ & $7.4 \%$ \\
QContinuity & $\approx 15 \%$ & $\approx 19 \%$ & $\approx 13 \%$ \\
\hline
\end{tabular}

Note: QContinuity error is estimated as the sum of the standard deviations in the individual components of the calibration uncertainty divided by the square root of the number of calibration events plus the sum of the standard deviations of the velocity and area precision which are related to the metering event.

\section{Calibration Uncertainty}

$\mathrm{Q}_{\text {Manning }}$ : The calibration consists only of the computation of the average $\mathrm{HC}$ value over all calibration events and the standard deviations of the individual $\mathrm{HC}$ values was computed. In order to reflect the fact that the average was used to compute the calibration factor, the standard error of estimate was used to characterize the calibration uncertainty. The standard error of estimate was computed as $\sigma_{H C} / \sqrt{N}$ in which $\sigma_{\mathrm{HC}}$ is the standard deviation of the $\mathrm{HC}$ values while $\mathrm{N}$ is the number of calibration events. 
$\mathrm{Q}_{\text {Continuity: }}$ Uncertainty in the meter calibration was assumed to be associated with two individual components:

1. The estimate of the uncertainty in the peak velocity which was computed from the standard deviation of the difference between the peak velocities recorded by the two meters; and

2. Uncertainty in the conversion from average to peak velocity which is computed from the standard deviation of the individual $R$ values. Again, since the calibration factors (meter gain to adjust the peak velocity and the $\mathrm{R}$ value) represent an average over all individual calibration events, the standard error of estimate was used to compute the calibration uncertainties associated with these variables.

\section{Extrapolation Uncertainty}

Since the calibration events were for dry weather conditions and at substantially lower depths than the data for calibrating the hydraulic model, the possibility of systematic deviations of the meter calibrations with depth admits the possibility of considerable error in the metered flows. There are a number of factors that could introduce a systematic variation between the metered and actual discharges including:

1 A systematic variation in the average to peak velocity ratio with relative depth. It was assumed that the $\mathrm{R}$ value is meter stationspecific but constant over the depth range and the basis for this assumption may be questioned. The calibration data for individual events were examined as a function of relative depth in order to determine whether or not any systematic trends can be observed. Data for two individual meters with the largest change in relative depth over the range of calibration flows are presented in Figure 13.1 while the calibration data for all twelve meters is included in Figure 13.2. Although the $\mathrm{R}$ values appear to increase with relative depth for both meters in Figure 13.1, the opposite trend is indicated for other meters in Figure 13.2 and the variations for an individual meter are generally within the uncertainty in the calibration measurements and no trend in the data is apparent.

2. Lack of uniform flow due to backwater or other effects, thus invalidating the assumption upon which $\mathrm{Q}_{\text {Manning }}$ is based. Any systematic deviations might be station-specific but in general, an increasing backwater effect with discharge should result in a systematic over-estimation of discharge with increasing relative depth due to the fact that the water surface slope would be less than the pipe slope, i.e. the $\mathrm{HC}$ value should decrease with relative depth. Figures 13.3 and 13.4 present the variations in $\mathrm{HC}$ with relative depth 


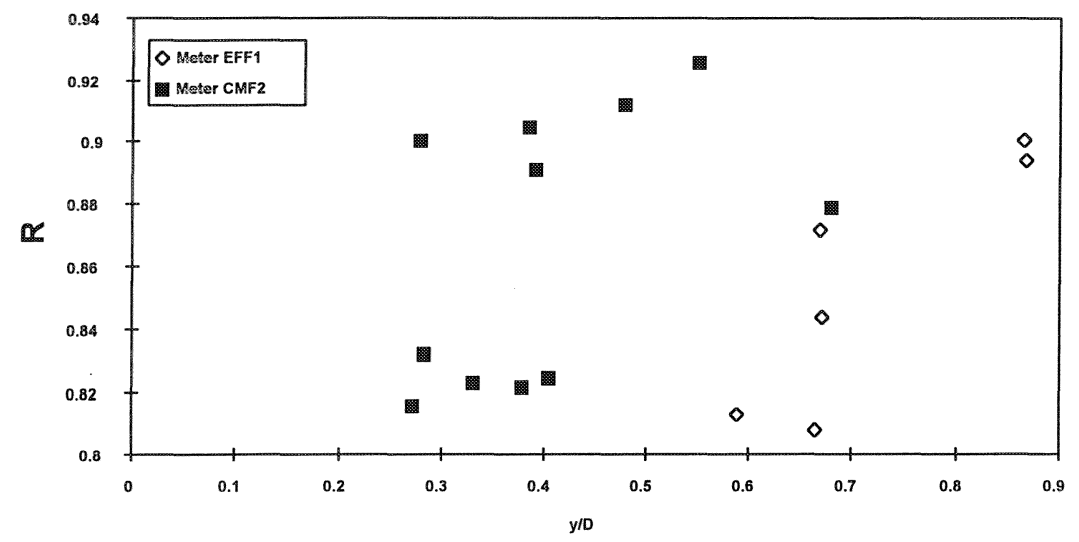

Figure 13.1 Variation in average to peak velocity with relative depth for selected meters.

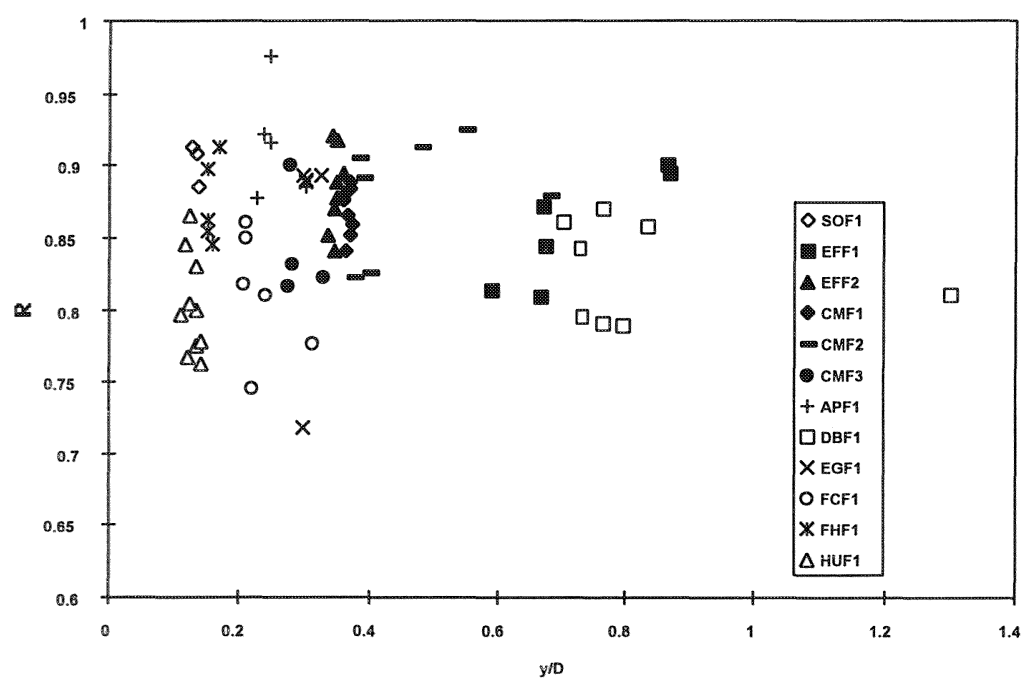

Figure 13.2 Variation in average to peak velocity with relative depth for all meters.

for two meter stations which show an opposite trend of increasing $\mathrm{HC}$ with depth; this trend was observed for most of the other meter installations. 


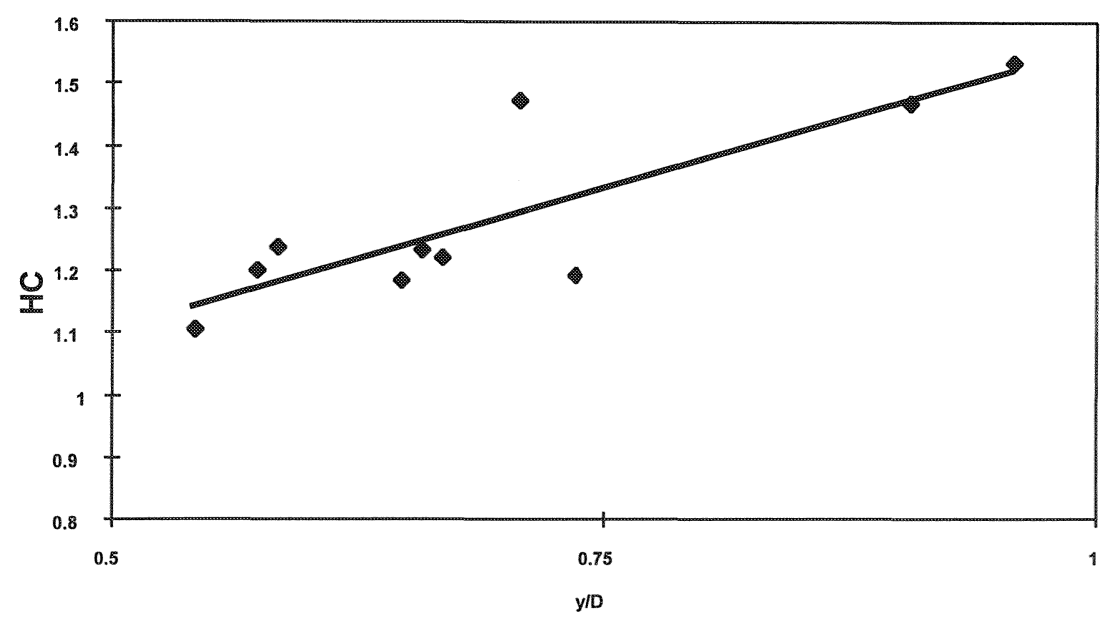

Figure 13.3 Variation in HC with relative depth for the meter NWF2.

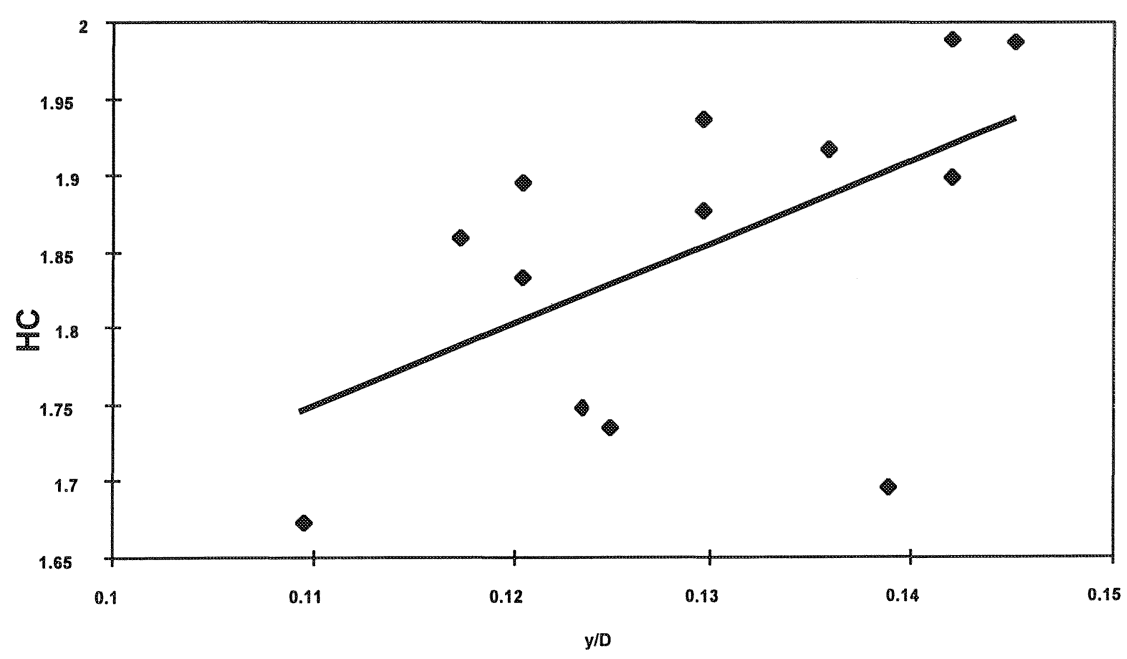

Figure 13.4 Variation in HC with relative depth for the meter HUF1.

\section{Overall Uncertainty}

The overall uncertainty in the measurement of discharge may be estimated by summing the individual contributions in each of the three areas noted above. This was done for three representative meter stations and the results are presented in Tables 13.1 and 13.2, for $\mathrm{Q}_{\text {Manning }}$ and $\mathrm{Q}_{\text {Continuity }}$, respectively. As 
noted above, the standard error of estimate was used to estimate the uncertainty in calibration coefficients where these coefficients are obtained from the averages of a set of calibration data. Although recognizing the possibility of an extrapolation error on the average to peak velocity ratio, this was not included in Table 13.2 due to the inability to detect clear trends in the calibration data for the meters in question. The extrapolation uncertainty in $\mathrm{HC}$ was estimated by fitting a trend line to the $\mathrm{HC}$ variation with relative depth and extrapolating to the full pipe condition. It is seen from Table 13.1 that this is a major contributor to the meter uncertainty for the estimate of $\mathrm{Q}_{\text {Manning }}$ and cautions against the use of this type of meter in an application which is far outside the range of calibrated depths. On the other hand, the large number of individual components in the $\mathrm{Q}_{\text {Continuity }}$ determination contribute to a larger overall meter uncertainty when the extrapolation uncertainty is neglected with typical uncertainties of the order of 15 to $20 \%$ and somewhat higher than estimated by the meter vendor for these stations.

\subsubsection{Evaluation of Metering Records}

It was subsequently decided to make a more detailed investigation at one meter site (HUF1) in order to gain some sense of the validity of the uncertainty estimates presented in Tables 13.1 and 13.2. This particular meter is in a 4.11 $\mathrm{m}$-diameter pipe which was calibrated at depths less than $0.6 \mathrm{~m}$ and therefore potentially subject to a significant extrapolation error. An additional acoustic Doppler meter was installed at approximately the pipe mid-depth so that the velocity indicated by each Doppler meter could be checked at higher flow rates. The purpose of this action was to determine whether the transmission of the signal through a sediment laden flow might affect the velocity measurement. In addition, a plan to estimate the flow rate by the dye dilution method as an independent method for discharge determination was developed. Although the intention was to implement these procedures for high discharge conditions, there were very few rainfall events over the time period allotted for this investigation. Only one event, on January 28, 1994 resulted in a significant record where both velocity meters were operational for an extended period of time. Dye dilution studies during high flow events have not yet been conducted.

\section{Comparison Between Two Doppler Velocity Meters}

The second Doppler velocity meter was activated whenever the flow depth at the meter station was greater than about $1.4 \mathrm{~m}$. This occurred for the six dates. One problem noted in the velocity records for the second meter (identified as MO2) was that whenever the water depth was at the level at which it was initially activated, an erroneously low velocity was registered. In these situations the recorded velocity may be half or less of the velocity recorded by the bottom 
mounted meter. In order to avoid errors associated with this occurrence, data was discarded at the beginning and ends of the meter records for $\mathrm{MO} 2$ whenever it appeared that this effect was present. Consequently, the entire record for one of the six dates was discarded. A total of 44 different velocity comparisons (recordings were made at ten minute intervals) over the five remaining dates were judged to be valid.

The MO2 meter was not verified in place due to the difficulty of calibrating at high discharges. Therefore, the possibility exists of a velocity offset between the two meters. The mean and standard deviation of the differences between the two meter readings were computed; these were 0.070 and $0.108 \mathrm{~m} / \mathrm{s} \mathrm{respec-}$ tively. The difference of $0.070 \mathrm{~m} / \mathrm{s}$ (the bottom velocity meter registered greater velocity on average) represents a difference of approximately $4 \%$ of the velocity measured (ranging from 1.43 to $1.83 \mathrm{~m} / \mathrm{s}$ ) and thus the difference between the two meters is relatively small. An examination of the records indicates that MO2 registers greater than the bottom velocity meter as the water level first rises high enough to activate it, but then falls below it later in the record. This trend is not sufficiently clear and the number of measurement events are too small to draw definite conclusions, and the effect is small in any case. The standard deviation of $0.108 \mathrm{~m} / \mathrm{s}$ represents $6.4 \%$ of the average velocity for the bottom velocity meter. In the previous analysis, the precision with which velocity could be measured with the Doppler meter was estimated to be approximately $4 \%$ for station HUF1. Assuming that the precision is the same for the additional meter $\mathrm{MO} 2$, the $6.4 \%$ standard deviation falls within the uncertainty in the difference between the two meters. Other components of the uncertainty in discharge determination (such as depth measurement or the peak to average velocity ratio) cannot be assessed from this data set.

\section{Results of Dye Dilution Study}

Dye dilution studies were performed on two dates, October 25 and 28, 1993 and involved approximately 45 minutes of dye sampling for which discharges were recorded at five minute intervals. Discharge records with both the stagedischarge calibration $\left(\mathrm{Q}_{\text {Manning }}\right)$ and the Doppler meter $\left(\mathrm{Q}_{\text {Continuity }}\right)$ were available for this same time period. The discharge computed by the dye dilution procedure for the October 25 event varied from 0.55 to $0.58 \mathrm{~m}^{3} / \mathrm{s}$ with an average value of $0.564 \mathrm{~m}^{3} / \mathrm{s}$. The variation of the discharge over the sampling period appears to be fairly random with a slight drop in flow rate over the course of the measurement. The metered discharges for the same period also indicate that the flow rate was relatively constant during the same time period. The record for $\mathrm{Q}_{\text {Manning }}$ indicates a discharge of approximately $0.67 \mathrm{~m}^{3} / \mathrm{s}$ while $\mathrm{Q}_{\text {Continuity }}$ indicates a discharge of about $0.71 \mathrm{~m}^{3} / \mathrm{s}$ with a trend of slightly decreasing discharge over the time interval for which the dye dilution study was performed. The discharge computed by the dye dilution method for the October 28 event 
varied from 0.48 to $0.55 \mathrm{~m}^{3} / \mathrm{s}$ with an average value of $0.50 \mathrm{~m}^{3} / \mathrm{s}$. The first three discharge values are greater than subsequent readings; however discounting these as erroneous, due to some sort of measurement error, only drops the average flow to $0.49 \mathrm{~m}^{3} / \mathrm{s}$. The metered discharges for the same period indicate that the flow rate decreased slightly during the same time period. The records for both $\mathrm{Q}_{\text {Manning }}$ and $\mathrm{Q}_{\text {Continuity }}$ indicate a discharge of about $0.67 \mathrm{~m}^{3} / \mathrm{s}$ over the time interval for which the dye dilution study was performed.

The discrepancies between the discharge determined from the dye dilution study and the other methods are greater than can be explained on the basis of estimated uncertainties in discharge measurement. In Tables 13.1 and 13.2, the estimated uncertainty in discharge measurement for meter HUF1 was about $\pm 9 \%$ for $\mathrm{Q}_{\text {Manning }}$ and $\pm 15 \%$ for $\mathrm{Q}_{\text {Continuity. Observed deviations range from } 15.3 \%}$ for $\mathrm{Q}_{\text {Manning }}$ on October 25 to around $26 \%$ for both $\mathrm{Q}_{\text {Manning }}$ and $\mathrm{Q}_{\text {Continuity }}$ on October 28.

\section{Large Discharge Metering}

In order to investigate the nature of any possible extrapolation errors, The velocity records for meter station HUF1 were examined to determine the differences between $\mathrm{Q}_{\text {Manning }}$ and $\mathrm{Q}_{\text {Continuity }}$ recorded at higher flow rates. Flow data was provided for the period between April 6 and July 17, 1992, for October 10 through December 18, 1993 and for the events which activated the meter M02 in 1994. This data is in the form of discharges at ten minute intervals for both $\mathrm{Q}_{\mathrm{Manning}}$ and $\mathrm{Q}_{\text {Continuity }}$. Rainfall events that triggered an increase in discharge at station HUF1 were identified from the data records. The estimate of $\mathrm{Q}_{\text {Manning }}$ should be incorrect on both the rapidly rising and rapidly falling portions of the hydrograph. The rising portion should be associated with an underestimate of the discharge as the friction slope (the flow acceleration will contribute to this as well) should be greater than the channel slope as the flood wave propagates down the pipe. On the falling leg of the hydrograph, the opposite should be true due to a deceleration of the flow. A detailed inspection of several rainfall events verified this relative trend. A representative plot of the two discharge records for a typical event is presented in Figure 13.5 although it is obscured by the fact that the magnitudes of the discharge peaks from the two meters do not correspond. It was decided to use data only at the peak flow rate for an individual event; this also simplified the data manipulation. A ratio of $\mathrm{Q}_{\text {Continuity }}$ to $\mathrm{Q}_{\text {Manning }}$ was computed at each local peak in the depth hydrograph for HUF1 for which the depth exceeded about $0.76 \mathrm{~m}$ and for which both discharge measurements were recorded. The ratio of these is presented in Figure 13.6. The data are broken into two sets depending upon whether the measurements were taken before or after June 6, 1992. The Doppler meter was replaced at HUF1 on June 6, 1992 when it was interpreted as providing a faulty signal. Figure 13.6 shows a distinct 


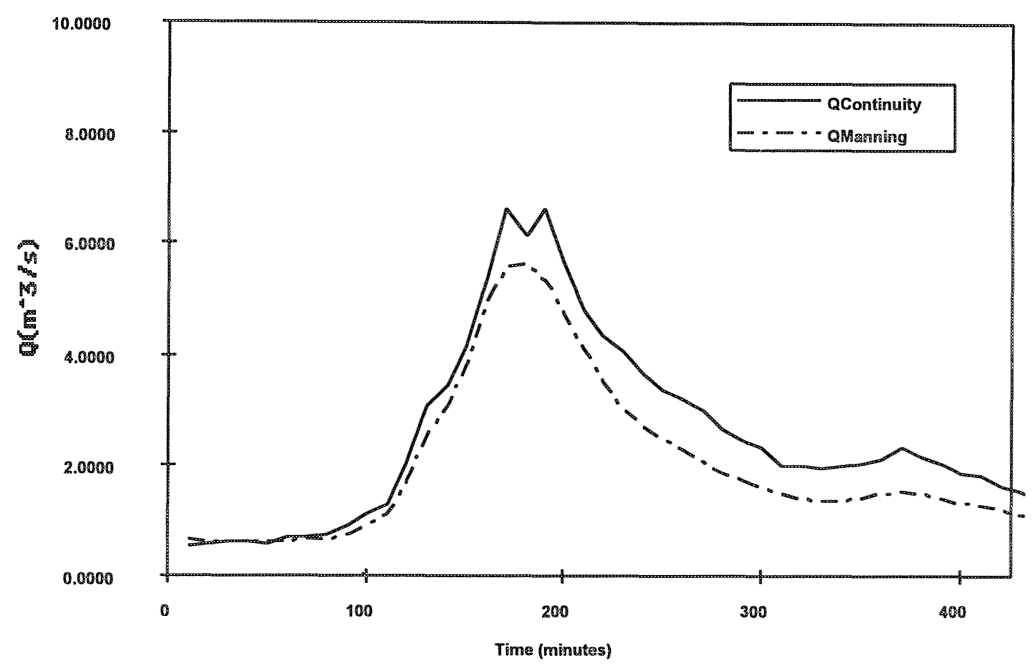

Figure 13.5 Comparison of discharge hydrographs for $\mathrm{Q}_{\text {Manning }}$ and $\mathrm{Q}_{\text {Continuity }}$ for a typical storm event.

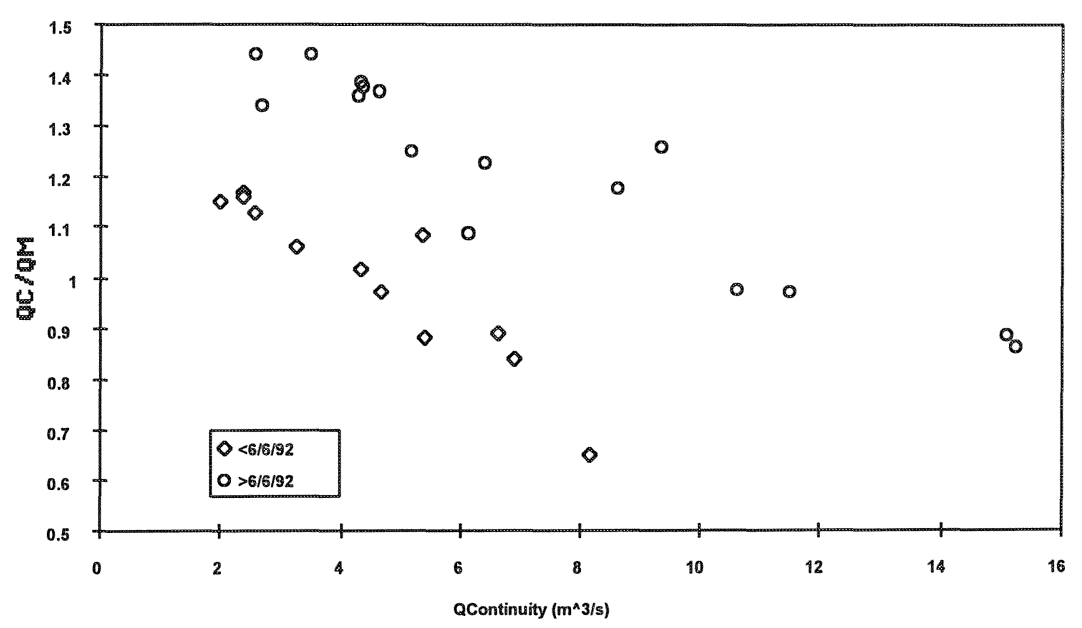

Figure 13.6 Ratio of $\mathrm{Q}_{\text {Continuity }}$ to $\mathrm{Q}_{\text {Manning }}$ determined at discharge peaks for storm events.

difference in the magnitude of the ratios for the period prior to June 6 and all data collected thereafter. However, the trends in the ratios are very similar both before and after the meter replacement with an offset in the magnitudes. The meters at station HUF1 were calibrated at discharges between about 0.54 and $1.10 \mathrm{~m}^{3} / \mathrm{s}$ 
(prior to the June 6 replacement date) and so the discharge ratio should be close to 1.0 in that range. This is apparent in the dry weather flow plots for late 1993 and the fact that the average value of the ratio for a four day dry weather period $(6 / 13 / 92-6 / 17 / 92)$ is 0.98 . This range of discharges is not presented in Figure 13.6 since only higher flow rates associated with storm peaks are included. As the discharge $\left(\mathrm{Q}_{\text {Continuity }}\right)$ increases from about $0.71 \mathrm{~m}^{3} / \mathrm{s}$, the ratio $\mathrm{Q}_{\text {Continuity }} /$ $\mathrm{Q}_{\text {Manning }}$ increases to about 1.5 at a discharge of about $2.1 \mathrm{~m}^{3} / \mathrm{s}$. This ratio decreases until the two recorded discharges are nearly equal at the highest flows, which have a flow depth about two-thirds the pipe diameter.

In Figure 13.4, it is indicated that the hydraulic coefficient tends to increase with relative depth over the range of the calibrations. A linear extrapolation of this trend to a full pipe condition would result in about a $40 \%$ increase in the hydraulic coefficient above the average value determined in the calibrations and used to determine $Q_{\text {Manning }}$. However if the hydraulic coefficient did in fact increase, then the discharge computed using the average low flow coefficient would be too low and therefore the ratio $\mathrm{Q}_{\text {Continuity }} / \mathrm{Q}_{\text {Manning }}$ would be too large. Although the ratio is greater than one, this cannot be the explanation for the decreasing ratio indicated in the figure, since the discrepancy becomes less with increasing discharge rather than greater. Therefore, it is concluded that there must be some other explanation for the variation noted. It is not known which of the two discharge determinations are correct due to the lack of an independent way of verifying the flow rate, but it is clear that there is an extrapolation error in at least one of the discharge measurements that is of the order of $50 \%$ for this metering station. An educated guess would be that the error is in $\mathrm{Q}_{\text {Manning }}$, because the two different Doppler meters (prior and subsequent to June 6, 1992) show similar trends.

\subsection{Conclusions}

An analysis was performed in order to estimate and quantify sources of uncertainty in the metering of discharge by two types of low loss meter that were installed to meter flow in a sewer system. These particular meters were calibrated in-situ during dry weather flow conditions in which discharges were substantially less than the range for which results were to be obtained for purposes of calibrating a numerical hydraulic model. In addition to issues associated with meter uncertainty, this calibration approach admits the possibility of considerable extrapolation error if the assumptions upon which the meter calibration is founded are not satisfied. An estimate of the relative contributions of precision, calibration, and extrapolation uncertainty indicate that extrapolation uncertainty may be a controlling factor in overall meter precision. Even when the possibility of extrapolation uncertainty is discounted, the meter uncertainty for the acoustic 
Doppler meter was estimated to be of the order of 15 to $20 \%$ which is at the limit of the stated calibration goals for the development of the hydraulic model. Given the estimated levels of uncertainty for these meters, these calibration goals were probably unrealistic.

There is clear evidence of a major extrapolation error in at least one of the discharge measurement methods as the two disagree by about $50 \%$ for certain ranges of discharges. The ratio of the two flow rates when plotted against system discharge quite clearly indicates a systematic variation, indicating that the calibration method for at least one of the flow rates is inadequate. Based on the limited information, it is suggested that the $\mathrm{Q}_{\text {Manning }}$ measurement is in error, but this cannot be verified without additional independent discharge measurements at higher flow rates. This finding indicates that all discharges which have been estimated by extrapolation far outside the range for which the meters were calibrated should be viewed with caution unless additional verification is obtained.

Notation

\begin{tabular}{|c|c|}
\hline A & Flow area \\
\hline $\mathrm{F}_{\mathrm{n}}$ & $\begin{array}{l}\text { Manning } \mathrm{n} \text { adjustment factor for partially full flow in circula } \\
\text { pipe }\end{array}$ \\
\hline $\mathrm{HC}$ & Hydraulic coefficient used to determine $\mathrm{Q}_{\text {Manning }}$ \\
\hline & Manning n \\
\hline $\mathrm{Q}_{\text {Continuity }}$ & Discharge determined with acoustic Doppler meter \\
\hline $\mathrm{Q}_{\text {Manning }}$ & Discharge determined on basis of uniform flow assumption \\
\hline & Ratio of average to peak velocity \\
\hline $\mathrm{R}_{\mathrm{h}}$ & Hydraulic radius \\
\hline & Sample standard deviation \\
\hline & Standard error of estimate \\
\hline & Pipe slope \\
\hline & Average flow velocity at meter station \\
\hline & Maximum flow velocity in flow cross-section \\
\hline & Standard deviation of $\mathrm{HC}$ values \\
\hline
\end{tabular}

\section{References}

Camp, T. R. (1946) “Design of Sewers to Facilitate Flow," Sewage Works Journal, Vol. 18, pp. 3-16.

Camp, Dresser and McKee (1993a) "Model Calibration and Validation Procedure," Technical Memo 2, DWSD Combined Sewer Overflow Study.

Camp, Dresser and McKee (1993b) "Flow Metering Error Analysis," Technical Memo 18, DWSD Combined Sewer Overflow Study. 
Dearden, H.T. (1992) “Achieving Flow Accuracy,” Intech, Vol. 39 , pp. 37-37.

Gordon, R.L. (1989) “Acoustic Measurement of River Discharge,” Journal of Hydraulic Engineering, Vol. 115, No. 7, pp. 925-936.

Granger, R.A. (1988) “Experiments in Fluid Mechanics," Holt, Rhinehart, and Winston, Inc., New York.

ISO 5168-1968 "Measurement of Fluid Flow - Estimation of Uncertainty in a Flow-Rate Measurement," International Organization for Standardization.

ISO-748-1979(E) "Liquid Flow Measurements in Open Channels - Velocity-area Method," International Organization for Standardization, 2nd ed., 1994.

Parshall, R.L. (1926) "The Improved Venturi Flume," Transactions ASCE, Vol. 89, pp. 841-851.

Pomroy, J. (1996) "Selecting the Right Flowmeter," Chemical Engineering, pp. 94-102. 
